\title{
LA INTERJECCIÓN COMO NÚCLEO ORIGINARIO DEL LENGUAJE ORAL
}

NOTAS A LA HISTORIA DE UNA POLÉmiCA FILOSÓFICO-LINGÜlSTICA

- La noción de interjección en la tradición gramatical

La interjección es uno de los conceptos gramaticales que ha originado más discusiones a lo largo de la tradición lingüística. Su origen, naturaleza y función han sido descritos de formas dispares $\mathrm{y}$, hoy día, siguen constituyendo objeto de polémicas.

Los griegos no la consideraron como parte de la oración, la relacionaron con el verbo, la situaron entre los adverbios o la interpretaron como $a \lambda \sigma \gamma \sigma \iota$, elementos fuera del $\lambda \sigma_{\gamma} \circ \mathrm{s}_{\mathrm{u}}$ oración ${ }^{1}$.

Los romanos, a partir de Remmio Palaemon, la definen como parte de la oración; eso lo podemos comprobar en la definición de Donato que, con algunas variaciones, se repite a lo largo de la Edad Media:

pars orationis significans mentis affectum voce incondita 2.

1 Interjectio, 'intercalation', 'parenthèse' est, comme il a déjà été dit, la seule notion de classe qui ne remonte pas directement à un modzle grec. Les $G$ recs désignaient les exclamations et autres mots semblables par le terme de $\alpha_{\lambda} \sigma \gamma_{\sigma}$, les caractérisant ainsi comme des mots situés en dehors du $\lambda \sigma \gamma \circ \varsigma$, de la proposition, et, par là, en dehors du langage articulé et de la raison, elle aussi appellée $\lambda$ b́os..

Bróndal, VigGo, Les parties du discours, partes orationis. Etudes sur les categories linguistiques. Traduction française par Pierre Naert. Einar Munksgaard, Copenhague, 1948, pág. 29.

2 Cf. KRIL, H., Grammatici Latini, Lipsiae, 1857-74. 
Tomás Erfurt la glosa de la siguiente manera:

Aquella parte de la oración que determina al verbo o al adjetivo, expresando los afectos o movimientos del alma. Y esto es lo que Donato quiso expresar cuando dijo que la interjección es aquella parte de la oración que expresa un afecto del alma, con voz no conocida 3.

Nebrija no la clasifica como categoría gramatical independiente, sino que la engloba dentro de los adverbios:

Los latinos, como diximos en otro lugar, pusieron la interjección por parte de la oración, distinta de las otras; pero nos otros, a imitación de los griegos, contamos la con los adverbios. Assi, que será interjección una de las significaciones del adverbio, la cual significa alguna passión del ánima, con boz indeterminada, como ai, del que se duele; hahaha, del que se rie; tat, tat, del que vieda; assí de las otras partezillas por las cuales demostramos alguna passión del ánima 4.

Villalón, sigue a los gramáticos griegos y, por lo tanto, no considera a las interjecciones como partes de la oración. Las describe, tras los adverbios, como «bozes que pronunciadas denotan el affecto interior del alma» 5 .

En el «anónimo» de la VTIL y BREVE INSTITVTION para aprender los principios y fundamentos de la lengua Hespañola, se altera el número de las partes de la oración, «se rompe la magia de las ocho partes», consagrado por griegos y latinos ${ }^{6}$. La clasificación de este tratado, sin embargo, es análoga a la de Donato, con la adición del artículo. La interjección, considerada como tal parte, se describe mediante listas tomadas, en su integridad, del autor latino y organizadas, a partir de un criterio significativo, en cuatro tipos: de alegría, de dolor, de admiración y de miedo.

Scalígero, frente a la definición tradicional, traza la siguiente:

Est igitur Interiectio nota animi affecti, quae nullius orationis indiget adjumento ?.

3 ERfuRT, TomÁs DE, Gramática Especulativa. Traducción y estudio preliminar de Luis Farrés, Buenos Aires, Losada, 1947, pág. 133.

4 Nebrius, E. A. DE, Gramática de la Lengua Castellana. Ed. preparada por Antonio Quilis, Madrid, Editora Nacional, 1981, pág. 198.

3 Vrulalón, Gramática Castellana. Edición facsimilar y estudio de Constantino García, Madrid, C.S.I.C., 1971, pág. 49.

6 VTIL Y BREVE INSTITVTION para aprender los principios y fundamentos de la Lengua Hespañola, Lovaina, 1555. Edición facsimilar con Estudio e Indice de Antonio Roldán, Madrid, C.S.I.C., 1977, pág. 112.

$7 \mathrm{~K}$ IIL, op. cit., IV, pág. 306. 
El Brocense no admite la interjección como una de las partes de la oración y argumenta de la siguiente manera:

Quod naturale est, idem est apud omnes. Sed gemitus et signa laetitiae idem sunt apud omnes: sunt igitur naturales. Si vero naturales: non sun partes orationis. Nam eae partes, secundum Aristotelem, ex instituto, non natura debent constare ${ }^{8}$.

Sabemos que el Brocense caracteriza el lenguaje humano como instrumento «instituido» por el hombre que impuso nombre a las cosas tras intensa «deliberación». Tampoco acepta que la interjección pueda considerarse como adverbio:

Interiectionem Graeci adverbiis annumerant. Sed falso. Nam neque voces latinae, aut Graecae sunt, etiam si Latinis aut Graecis litteris scribantur. Sed signa tristitiae, aut laetitiae, qualia in auibus, aut quadrupedibus, in quibus tamen, nec vocem, nec orationem concedimus 9.

La Gramática General y razonada de Port-Royal se sigue inscribiendo en la misma línea de pensamiento que la Minerva; adopta idéntica actitud metodológica ante el estudio de la lengua y persigue la misma meta, aunque ambas lleguen a resultados diferentes $y, a$ veces, contradictorios ${ }^{10}$. Define las interjecciones de la siguiente manera:

8 Minerva seu de causis linguae latinac, I, 2. Se puede consultar con facilidad la traducción e introducción realizadas por Fernando Rivera Cárdenas, en la edición de Cátedra, Madrid, 1976. Sobre la aportación del Brocense al tema de la interjección y su posible base en Vives, vid. Almela Pérez, R., Apuntes gramaticales sobre la interjección, Murcia, Secretariado de Publicaciones de la Universidad de Murcia, 1982, págs. 81-85.

- Constantino García se pregunta por la naturaleza de las interjecciones en la opinión del Brocense ya que no las considera ni como oraciones ni como partes de las mismas, sino signos de tristeza o alegria independientes del lenguaje. Advierte cómo Perizonio, en la nota 6 al capítulo 2 del libro I de la Minerva, juzga que mejor será colocarlas dentro de los adverbios que excluirlas de las partes de la oración, y que, además, hay interjecciones que no son naturales, sino que significan «ex instituto».

Esta postura negativa, de exclusión -advierte Constantino García- la lleva a cabo a través de la Minerva pero en su manual práctico, las Verae brevesque Grammatices latine, Salamanca, 1572, aunque no les dedique un lugar aparte, al tratar de la clasificación de los adverbios, los incluye entre ellos, ya que afirma la existencia de adverbios «dolentis, paventis, silentis, exclamationis...». Constantino Garch, Contribución a la Historia de los «Conceptos Gramaticales. La aportación del Brocense», Madrid, C.S.I.C., 1960.

Según R. Almela, «el Brocense repite las palabras que setenta años antes había escrito Nebrija: Nos otros, con los griegos, no distinguimos la interjección del adverbio.' ¿No pudo haber conocido el Brocense estas ideas de Nebrija?», op. cit., páginas 83-84.

10 Véase la introducción de Ramón Morillo-Velarde Pérez a su edición de la 
Las interjecciones son palabras que tampoco significan nada fuera de nosotros, sino que son voces, más naturales que artificiales, que indican los movimientos del alma, tales como: ha, $\delta$, heu, helas, etc. 11 .

\section{- La noción de interjección en la filosofía sensualista}

El tema del origen del lenguaje considerado desde la perspectiva de los filósofos empiristas, actualiza el problema de la naturaleza de la interjección y lo replantea sobre bases nuevas. A este respecto, merecen nuestra atención las teorías sensualistas de dos autores franceses: Condillac y Destutt de Tracy. Analicemos cada una de ellas por separado.

Condillac, en el capítulo primero de su Gramática, incluida en el Curso de Estudios para la instrucción del Principe de Parma ${ }^{12}$, describe el «lenguaje de acción» como el medio primero de que se valen los hombres para comunicarse sus pensamientos. Distingue tres procedimientos diferentes:

- Los ademanes.

- Los movimientos del semblante.

- Los acentos inarticulados.

Por ademanes entiende los movimientos de los brazos, de la cabeza y de todo el cuerpo, cuando se acerca o se aparta de un objeto; en otros términos, las actitudes que adopta el hombre a partir de las impresiones que se transmiten al alma. Según esta definición, todos los sentimientos del alma pueden ser expresados por las actitudes del cuerpo:

Las quales pintan de un modo sensible la indiferencia, la incertidumbre, la irresolución, la atención, el temor y el deseo mezclados entre si; el combate de las pasiones sucesivamente superiores las unas á las otras; la confianza y la desconfianza, el goce tranquilo y el goce inquieto; el placer y el dolor; el pesar y el gozo; la esperanza y la desesperación; el odio, el amor, la cólera, etc. ${ }^{13}$.

A los ademanes y actitudes corporales se unen los «movimientos del semblante» que dotan de elegancia al lenguaje de acción:

¿Gramática General y Razonada» de Port-Royal, Madrid, Sociedad General Española de Librerías, S. A., 1980, pág. 13.

11 Ibidem, pág. 121. Puede consultarse también RozAND Donzte, La Gramática General y Razonada de Port-Royal. Contribución a la historia de las ideas gramaticales en Francia, Buenos Aires, Eudeba, 1970.

12 Condiluac, Curso de estudios para la Instrucción del Principe de Parma, t. I, Gramática, Cádiz, Imprenta de Carreño, 1813, pág. 143 y sigs.

13 Ibidem, págs. 144145. 
Pero la elegancia de este lenguaje está en los movimientos del semblante, y mayormente en los movimientos de los ojos. Estos movimientos dan la última mano al quadro que las actitudes no han hecho más que bosquejar, y expresan las pasiones con todas las modificaciones de que son susceptibles.

Los acentos inarticulados, por el contrario, ejercen una función complementaria, ya que sólo llaman la atención sobre los ademanes y movimientos corporales:

Este lenguaje habla únicamente á los ojos, y por consiguiente sería muchas veces inútil, si por medio de gritos no llamásemos las miradas de aquellos á quienes queremos dar á conocer nuestros pensamientos. Estos gritos son los acentos de la naturaleza; varían según los sentimientos que nos afectan, y se llaman inarticulados, porque se forman en la boca sin ser modificados por la lengua, ni por los labios. Aunque estos gritos son capaces de hacer una impresión viva en aquellos que los oyen, no expresan, sin embargo, nuestros sentimientos sino de un modo imperfecto, porque no manifiestan ni la causa que los produce, ni el objeto á que se dirigen, ni las modificaciones que los acompanan; pero invitan á observar los ademanes y los movimientos del semblante; y el concurso de estos signos acaba de explicar lo que sólo estaba indicado por los acentos inarticulados.

Estos acentos inarticulados constituyen el nivel más elevado del lenguaje de acción y, al ser producidos por los órganos de la voz, participan, de alguna manera, de ciertos caracteres del lenguaje articulado. Son las interjecciones de la gramática tradicional y representan el puente que une al lenguaje de acción con el lenguaje oral. Puede encerrar el contenido de una frase entera y su descripción no corresponde a los estudios estrictamente gramaticales.

Las interjecciones, $\delta$ aquellos acentos que, como hemos visto, son comunes al lenguaje de acción y al de sonidos articulados, son unas expresiones rápidas que equivalen algunas veces á frases enteras. No tienen lugar señalado, y por eso mismo son más expresivas. Ya den principio al discurso, ya le terminen, $\sigma$ ya le interrumpan parece que se nos escapan en el momento de producir su efecto.

A los acentos naturales del lenguaje de acción han añadido las lenguas palabras como estas: jay de mil, ‘Cielos!, |Dios! Nada tiene que advertir la gramática acerca de esa especie de palabras. Al sentimiento es al que pertenece usarlos con oportunidad 14.

Destutt de Tracy elabora su Gramática General, utilizando el método analítico «que es en realidad el único compatible con la naturaleza del

14 Ibidem, págs. $460-461$. 
entendimiento humano* ${ }^{15}$. Tras examinar la naturaleza de la proposición, pasa a estudiar los elementos que la componen. Comienza precisamente por la interjección ya que, según él, es el elemento que marca el origen del lenguaje oral, y une la distancia que separa el lenguaje de acción del lenguaje articulado.

... en el origen del lenguaje se compone una proposicion sólo de un gesto, $\delta$ de un grito, las primeras voces que se ofrecen son las que aun ahora explican por sí solas una proposición completa: estas voces son generalmente las que los gramáticos llaman interjecciones ${ }^{16}$.

Pero ensancha el contenido de este concepto ya que comprende, no sólo las tradicionales interjecciones, sino también otras voces llamadas partículas y los adverbios, que tienen por sí solos sentido completo, como si, no y otros. Estos elementos invariables no se relacionan con ningún otro, contienen implícitamente sujeto y verbo $\mathrm{y}$, todas las demás partes de la oración son fragmentos suyos destinadas a descomponerla. A pesar de su imperfección, el análisis de estas especies de voces ofrece la utilidad de guiarnos «á reconocer el mecanismo de la oración, de la cual son á un propio tiempo, forma primera y compendio» ${ }^{17}$.

De la «desintegración» de la interjección se originan, en primer lugar, los nombres y pronombres que ejercen la función de sujeto $y$, en segundo lugar, el verbo que desempeña el papel de atributo:

Cuando digo jay! la interjección, la exclamación, el grito, jay! significa toda la proposición yo padezco; y si digo yo lay!, ay no significa más que el atributo padezco.

De esta manera llega Destutt a la explicación del origen y definición del verbo y descubre los primeros pasos en la formación del lenguaje oral:

Véase, pues, descubierto precisamente este segundo elemento de la oración, esta voz tan maravillosa é inefable, sin ser menester inventarla á fuerza de ingenio: resulta inevitablemente de la separación del sugeto y el atributo y no se formó con habilidad suma de los demás elementos de la oración, antes vamos á verlos salir todos sucesivamente de su descomposición del mismo modo que él nace de la restricción puesta á la significación de la interjección.

15 Desturt, M., Conde de Tracy, Gramática General, traducida por Juan Angel Caamaño, Madrid, Imprenta de don José del Collado, 1822, pág. 72.

16 Ibidem, pág. 118.

17 Ibidem, pág. 120. 
El verbo, por lo tanto, al ser sólo una parte de la interjección, único elemento linguístico con valor significativo completo, exige la presencia de un sujeto - un sustantivo o pronombre-; sin éste, no tendría capacidad suficiente para expresar un juicio completo.

Destutt sigue este proceso de sucesivas «desintegraciones» para determinar el nacimiento de las otras partes de la oración: adjetivos, adverbios, partículas, etc.

En España la doctrina sensualista fue recibida de maneras opuestas. Mientras los herederos de la tradición escolástica la rechazaron con escándalo y la combatieron con dureza, algunos filósofos la siguieron entusiasmados.

Juan Justo García ${ }^{18}$, catedrático de matemáticas de la Universidad de Salamanca y diputado a Cortes por Extremadura en los años 182021, en sus Elementos de verdadera lógica, que reproducen casi literalmente la Ideología de Destutt-Tracy, defiende así dicha doctrina:

Mas no es justo que calle acerca de la nota grosera del materialismo con que, o por ignorancia o por malicia, se denigra la persona respetable del autor; como se desacreditó la de Condillac por los que, faltos de razones para impugnar su doctrina, defendieron su decrépito sistema con injurias y calumnias 19 .

Justifica de la siguiente manera el contenido y la metodología del sistema de Destutt-Tracy:

Yo me persuado a que su ilustre autor, que no ha tenido en toda ella otra guía que la observación y la experiencia, falto de estos auxilios, se ha abstenido de tratar estas materias en que se hallaba privado absolutamente de datos sobre qué discurrir. Creerá por fe la existencia del alma, su espiritualidad, su inmortalidad; pero como filósofo, se propuso hablar sólo del hombre, deduciendo de los hechos que en él observó el sistema de sus medios de conocer; creyó que era una temeridad formar hipótesis y aventurar aserciones sobre el alma separada del cuerpo, en cuyo sistema de ideas ni hay hechos que puedan apoyarlas ni aun palabras significativas con que se pueda hablar de ellas 20.

En la misma línea de defensa encontramos un estudio del P. Miguel Martel, catedrático de Ética en Salamanca, Prenociones fisiologicas so-

18 Cf. Menéndez Pelnyo, M., Historia de los Heterodoxos Españoles, II, Madrid, B. A. C., 1956, pág. 875 .

19 GaRcta, JuAn Justo, Elementos de verdadera lógica, Madrid, Imp. de don Mateo Repullés, 1821, p. IX.

20 Ibidem. 
bre el alma del hombre y la existencia de Dios ${ }^{21}$, así como dos obras de Prudencio María Pascual: Sistema de la moral o teoría de los deberes y Arte de pensar y obrar bien o filosofía racional y moral 2 .

Esta doctrina la sigue el Curso de Psicología y Logica ${ }^{23}$ que compusieron Felipe Monlau y José María Rey Heredia. Dicha obra define el lenguaje como «una colección de fenómenos orgánicos significativos de hechos psicológicos; o, en general, un sistema cualquiera de signos». Divide el lenguaje en natural - «signos relacionados naturalmente con la cosa significada - y en artificial — «signos cuya relación natural con las cosas significadas se halla modificada por la voluntad; o cuya relación es completamente arbitraria y convencional»-. Siguiendo a Condillac distingue también entre el lenguaje mudo, compuesto de gestos, movimientos y actitudes, y el vocal, formado de «voces» y que se subdivide en inarticulado - voces o gritos- y el articulado - palabras.

Para nuestro trabajo nos interesa tener en cuenta sus propias palabras sobre la naturaleza de dichos lenguajes orales:

La voz inarticulada representa el pensamiento en el estado sintético; y la voz articulada, que no es más que análisis, la descomposición o el desenvolvimiento de la voz inarticulada, debía representar los movimientos del análisis del pensamiento 24.

Monlau describe también el proceso evolutivo que recorre el lenguaje inarticulado para convertirse en articulado:

En el estado espontáneo el hombre no tiene otro lenguaje que el natural; no se expresa más que con gestos, movimientos y gritos. La forma de este lenguaje es sintética como su fondo. El signo es igual a la cosa significada (...). Pero el hombre debe pasar del estado directo al reflejo;

21 Estudio incluido en su obra Elementos de Filosofia Moral.

22 Publicado en Madrid en la Companía General de Impresores y Libreros, 1843, 3." edición.

23 Curso de Psicología y Lógica, escrito con arreglo al programa oficial de esta asignatura, para uso de los Institutos, Seminarios y Colegios de Segunda Ensefaanza, dos tomos: Psicología, por don Pedro Felipe Monlau; Lógica, por don Jose Marfa REY y HeRedia, Imp. de la Publicidad, a cargo de don Manuel Rivadeneyra, Madrid, 1849. El primer tomo (Psicologia) consta de 260 páginas y el segundo (Lógica) de 290 páginas. La segunda edición está editada en Madrid, Imprenta y Estereotipia de don Manuel Rivadeneyra, 1851; la tercera edición es de 1856 y la cuarta edición de 1858, impresas ambas en la citada imprenta de Manuel Rivadeneyra. Esta obra, declarada oficialmente de texto, fue adoptada en casi todos los institutos y colegios de Espana.

Estos datos han sido tomados de M. MoUReur DB Lrac, La teoria lingulfstica en la España del siglo XIX, Madrid, Editora Nacional, 1968, pág. 7 , nota 33.

24 Elementos de Psicología, pág. 189. 
este paso hacía necesario un lenguaje también reflejo. Los gestos y los movimientos espontáneos debieron pasar a ser intencionales, o a ser más o menos dirigidos por voluntad; los gritos o voces articuladas 25.

Se trata, por lo tanto, de una traducción fiel de la teoría de DestuttTracy sobre la evolución del grito a la palabra.

Rey y Heredia en la tercera parte de la obra, titulada Gramática, admite también la posibilidad del proceso lenguaje inarticulado lenguaje articulado, pero a condición de que no implique un convenio entre los hombres ni un estado previo de mutismo, sino un paso insensible del grito a la articulación:

Pudo el hombre sentir su propia fuerza expresiva, emplearla primero de una manera espontánea y después apoderarse de ella, someterla a su propia acción y usarla al cabo libre y reflexivamente 26.

Entre los gramáticos, el primero que se hace eco de la doctrina sensualista en España es don Lorenzo de Alemany en sus Elementos de Gramática castellana, dispuestos para uso de la juventud ${ }^{n}$. Caracteriza a la interjección con tres rasgos:

1. Palabra independiente de todas las demás.

2. Sirve para expresar los afectos del ánimo.

3. Envuelve casi un pensamiento entero.

Y las divide en siete tipos según su significación: de alegría, de dolor, de temor, de aversión, de admiración, para animar, para hacer callar.

En la nota al pie de página, para justificar que la interjección debe ser considerada como parte de la oración, apela a su condición de origen de todas las demás palabras:

Algunos gramáticos se fundan en esto para decir que la interjección no es en rigor parte del discurso, cuando no solamente debe deducirse que lo es, sino que consultando á los que han tratado la gramática con toda generalidad y filosofía, se infiere que es además la raíz u origen de todas las palabras 28.

25 Ibidem, pág. 188.

26 Elementos de lógica, pág. 177.

27 Imprenta de Juan Tib6, Lión, 1829.

28 Página 77.

LXVI, 3.0-4.o. -5 
Declara como muy probable la existencia de una etapa primitiva en la que se expresaran los pensamientos completos con una sola voz o interjección:

En efecto, es muy probable que en la infancia de las lenguas se supliesen los pensamientos enteros con una sola voz o interjección.

Y, a continuación, detalla el proceso de división por el que, sucesiva y gradualmente, van apareciendo los sustantivos, los adjetivos, el verbo sustantivo, los verbos adjetivos, el artículo, la preposición, el adverbio, y la conjunción. Señala también la función peculiar de cada uno de estos elementos:

Pero de esta interjección se fue dando poco á poco nombre a los objetos, y de aquí los sustantivos: se fue distinguiendo que algunos de ellos (los abstractos), como claridad, blancura, etc., envolvían en sí una cualidad, y de éstos se formaron los adjetivos, diciendo nieve blanca, en lugar de nieve blancura: se enlazaron estas dos palabras con el verbo para formar sentido perfecto, y ya se dijo nieve es blanca: se inventó una palabra que significara á la vez el verbo y el atributo, y de aquí los verbos adjetivos nieve blanquea; y finalmente por este mismo órden se inventarían el artículo para determinar el nombre la nieve blanquea; la preposición, para indicar las relaciones entre las palabras la nieve blanquea en todo tiempo; el adverbio, para espresar en una sola palabra la preposición y su complemento la nieve blanquea siempre, y finalmente la conjuncion, para unir y enlazar las palabras, y aun las proposiciones.

Hé aquí cómo la interjección no solamente es parte del discurso, sino también la raíz y origen de todas las palabras 29.

Gómez Hermosilla, en su Gramática General ${ }^{30}$, comienza tomando por texto estas palabras de un naturalista: «El universo no nos presenta más que materia y movimiento» y funda en la idea del movimiento material -aplicado luego por traslación a las ideas abstractas- su teoría sensualista del verbo activo, en oposición a la teoría ontológica del verbo único - el ser-, profesada por los aristotélicos. En cuanto al origen del lenguaje, se declara partidario de la onomatopeya ${ }^{31}$ :

El hombre formó, imitando del modo posible los movimientos que veía y los ruidos que escuchaba, ciertas palabras..., y como observo también que de estos movimientos de los otros cuerpos le resultaban a él

29 Página 78.

30 Gómez Hermosilla, J., Principios de Gramática General, Madrid, Imprenta Nacional, 1841, 3.' ed.

31 Herder (1744-1803) había subrayado el carácter natural-evolutivo del lenguaje, surgido de la imitación de los sonidos de la naturaleza y capaz de evolución y crecimiento continuos. 
mismo ciertas impresiones, es decir, otros movimientos verificados en la superficie exterior de su cuerpo, notando, verbigracia, que la presencia del sol le causaba cierta modificación que nosotros llamamos calor y el contacto de la nieve la que intitulamos frío, dijo también: 'El sol calienta, la nieve enfría'.

No cuenta a la interjección como parte de la oración. Apoya tal exclusión en cinco razones:

1. Porque tiene valor de oración completa.

2. Porque al surgir de modo involuntario directamente arrancadas de las sensaciones, «no pertenecen á la enunciación voluntaria y reflexiva del pensamiento, que es la que con propiedad llamamos hablax.

3. Son naturales $\mathrm{y}$, por lo tanto, están fuera del anúmero de los signos convencionales de las idéas, que son de los que tratan las gramáticas».

4. No exigen el estudio ni la consideración de los estudiosos ya que

Nada hay que decir acerca de las interjecciones, sino lo que todo el mundo sabe; y es que, siendo producidas por los movimientos maquinales que excitan en el órgano vocal las sensaciones actuales, 6 sus recuerdos, no expresan ninguna idéa determinada, sino la confusa de que entónces nos hallamos en una situación grata ó ingrata.

5. Finalmente, argumenta que si las interjecciones deben ser incluidas en las partes de la oración, también se tendrían que considerar como tales la risa, los suspiros y los sollozos, pues también expresan, y muy enérgicamente, los «afectos interiores del ánimo».

Arbolí, que a partir de una concepción filosófica neo-escolástica, compone su Gramática General en contra de la de Gómez Hermosilla, paradójicamente en sus explicaciones sobre la interjección, está muy próximo a las ideas de su adversario. No duda en reconocer la proximidad a los gritos o acentos naturales:

Son las palabras que más se acercan, ya por la sencillez de su mecanismo, ya en la espontaneidad de su expresión, á los gritos ó acentos naturales; y que siendo cada cual de ellas versión abreviada, pero completa, de un pensamiento perfecto, son incapaces de accidentes 32 .

\footnotetext{
32 Arbolf, Juan Jose, Compendio de las lecciones de Filosofia que se enserian en el Colegio de Humanidades de San Felipe Neri de Cddiz, tomo III: Gramatica General, Cádiz, Imp. de la Sociedad de la Revista Médica, 1846, pág. 62.
} 
Niega que puedan ser consideradas como partes de la oración ya que traducen juicios completos. Debemos recordar que ésta es, precisamente, su definición de oración gramatical. En su relación de las formas más usuales, incluye la afirmación sí y la negación no y argumenta que cuando se emplean absolutamente respondiendo a una pregunta, equivalen a oraciones completas y significan el acto de la razón asintiendo o disintiendo, afirmando o negando lo que se le propone.

Otras muchas gramáticas del siglo xIX, por ejemplo, las de Llera, Salleras, etc., o no se hacen eco de la doctrina que ve en las interjecciones el origen del lenguaje o la rechazan como lo hace Canalejas ${ }^{33}$.

\section{- La noción de interjección en la Lingüística moderna}

Ya dentro de las actuales corrientes de la Linguística, E. Sapir no está de acuerdo con que las interjecciones constituyan una prueba de la «motivación» del lenguaje oral y señala la diferencia que las separa de los sonidos involuntarios emitidos bajo el impulso de un dolor o de una emoción. Mientras que éstas son una «expansión más o menos automática de la energía emocional", las interjecciones, por el contrario, son «fijaciones convencionales de sonidos naturales». Por esta razón di-

\footnotetext{
33 «Se generalizó muy luego la convicción de que la doctrina de la onomatopeya solo servia para colocar al hombre en grado inferior a los brutos, que al fin poseían gritos propios; y los mismos filósofos sensualistas, como Condillac, rechazaron la doctrina, sustituyéndola con la de la interjección. El hombre llora, gime, solloza, ríe, y por medio de exclamaciones expresa el asombro, el gozo, el dolor, la ira; y estos gritos, estas interjecciones, fueron, dicen, el principio natural y real del lenguaje. Cierto es que en todas las lenguas existen interjecciones, pero la lengua no comienza verdaderamente, sino cuando concluyen las interjecciones, que son manifestaciones fisiológicas, en las cuales no existe siquiera la articulación de la voz. La comprobación de esta doctrina es fácil, observando cuándo y cómo empleamos las interjecciones voluntariamente, las empleamos sólo cuando la impetuosidad 6 la violencia nos hacen olvidar el uso del lenguaje ó nos impiden su empleo por un movimiento personal y puramente afectivo de nuestro ánimo.

Sería posible, confeccionando á la manera de los autores 6 creadores de lenguas universales, formar una compuesta de onomatopeyas é interjecciones; pero es segurisimo que este idioma no tendría la menor analogia con ninguna de las innumerables lenguas que se han hablado 0 se hablan sobre la tierra. Cierto es también que las interjecciones, ayudadas del gesto y expresión de la fisonomía, del ademán y de la actitud, podrían expresar los afectos y los deseos del hombre; pero ésta sería la expresión pantomímica y no el lenguaje en que se manifiesta el espíritu. Por último, las etimologías de las palabras que se suponían derivadas de interjecciones, han desaparecido por efecto de un análisis más detenido, y apenas se pueden indicar en las lenguas más que las puras interjecciones en su estado primitivo, que será el constante, el de ah!, oh!, ay!, etc., lo que demuestra que no han tenido carácter radical en la historia de las lenguas.» Canalejas, F. de P., Curso de Literatura General, Madrid, Imp. de la Reforma, 1868, págs. 177-178.
} 
fieren tanto en los diversos idiomas, ya que éstos las interpretan y acomodan a partir de las posibilidades de sus propias estructuras fónicas. Sapir concede a las interjecciones una importancia secundaria desde una perspectiva linguística $y$, en contra de lo que pudiera parecer a primera vista, su análisis sólo puede demostrar que aún esos sonidos, que todos convienen en considerar como los más cercanos a la expresión natural, sólo poseen naturaleza instintiva en un sentido superficial:

Así, pues, aunque fuera posible demostrar que el lenguaje todo se remonta, en sus fundamentos primordiales, históricos y psicológicos, a las interjecciones, no se seguiría de ello que el lenguaje sea una actividad instintiva. De hecho, todos los intentos de explicar de esa manera el origen del lenguaje han sido infructuosos. No existe una prueba tangible, ni histórica ni de ninguna otra especie, que demuestre, que el conjunto de los elementos del habla y de los procedimientos lingüisticos ha surgido de las interjecciones. Estas constituyen una parte muy reducida y funcionalmente insignificante del vocabulario de los diversos idiomas; en ninguna época ni en ninguna provincia lingüistica de que tengamos noticias podemos observar una tendencia notable a convertir las interjecciones en urdimbre inicial del lenguaje. En el mejor de los casos, no pasan de ser la orla decorativa de un amplio y complicado tejido ${ }^{34}$.

Gray no acepta tampoco que las interjecciones sean incluidas en el estudio estrictamente lingüístico ya que, en realidad, se trata de una actividad vocal refleja, con valores psicológicos y afectivos y sin contenidos linguísticos. Las falsas interjecciones como «stop! pueden ser consideradas como verbos o nombres, empleados elípticamente:

From the strictly linguistic point of view it is important to observe that true interjection neither possess nor ever have possessed so far as we can tell, any inflexion whatever ${ }^{35}$.

En esta misma línea también se sitúa Porzig, quien cataloga a las interjecciones como elementos dotados solamente de significación afectiva:

Alle Ausrufe sind Wertungen, bejahende oder verneinende, wie man leicht versteht, wenn man an ihren seelischen Ursprung in der Erregung denkt 36 .

34 SAPIR, E., El lenguaje, México, F. C. E., 1971, 3.• reimp., pág. 13.

35 GraY, L. H., Foundations of Language, New York, 1939, pág. 166.

36 Porzig, W., Das Wunder der Sprache, Probleme, Methoden und Ergebnisse der modernen Sprachwissenschaft, Bern, 1950, pág. 351. 
Vendryes también es partidario de excluir las interjecciones del ámbito lingüístico, ya que tanto su forma como sus contenidos difieren radicalmente de las llamadas «partes de la oración», portadoras de significados racionales:

La interjección representa una forma especial del lenguaje, el lenguaje afectivo, y, a veces, el lenguaje activo; en todo caso, queda fuera de la estructura del lenguaje intelectual ${ }^{37}$.

Lenz, por el contrario, concede a las interjecciones un lugar dentro del funcionamiento de la lengua $y$, como consecuencia, en el área propia de los estudios linguísticos. Defiende que la clasificación fundamental de las oraciones debe apoyarse en criterios psicológicos y las divide en exclamativas, declarativas e interrogativas. Define a la oración exclamativa como la expresión de un afecto por medio del lenguaje y advierte cómo se nota su carácter primitivo en la estrecha relación que guarda este tipo de oraciones con la interjección:

Esta es un elemento rudimentario, supervivencia de la época anterior a la formación del lenguaje humano propiamente tal, como se ve por la comprensibilidad casi inmediata que comparte la interjección con los gestos y acciones de las manos que acompañan al lenguaje sin entrar en relaciones con él 38 .

La analogía con los gestos -observa Lenz- no debe hacernos caer en el error de que las interjecciones sean sonidos «naturales». Se puede comprobar cómo cada comunidad linguística las pronuncia de un modo particular, conforme a sus tendencias fonéticas, y a menudo la misma interjección tiene significados distintos en diferentes lenguas. Estas reflexiones le llevan a concluir que «todas las interjecciones primitivas y secundarias no son partes de la oración, ni oraciones, sino que deben clasificarse como equivalentes de oración» ${ }^{39}$. Podemos recordar que para Wundt —el psicólogo en quien Lenz se inspiró- las interjecciones tampoco constituyen oraciones sino «eine vorsprachliche Stufe» 40.

Bröndal define la frase como un todo de naturaleza a la vez analítica y sintética, una combinación de sustancia y de función, tanto en sentido subjetivo como en sentido objetivo.

37 VendRYES, J., El lenguaje. Introducción lingüistica a la Historia, trad. de Manuel Montoliú, 2: ed., Barcelona, 1943, pág. 156.

30 Lenz, R., La oración y sus partes, Madrid, Centro de Estudios Históricos, 1920, página 41.

39 Ibidem, pág. 42.

\$0 WuNDT, Völkerpsychologie, I, pág. 320. 
A partir de esta definición se plantea la pregunta: ¿Existe una clase de palabra que responda a esta descripción, cuyos miembros sean pues, por definición, equivalentes de frases enteras?

La respuesta es afirmativa: se trata de las interjecciones. Recuerda cómo ya Vossius en el año 1635 las había definido como equivalentes a una frase, e, incluso, señala que su nombre, dado por los romanos, Interjectiones, quería decir precisamente «términos que interrumpen el curso de la frase», «incidentes» o «paréntesis». Piensa que las caracterizaciones de los griegos como elementos "alógicos» y de los modernos como "palabras de la naturaleza" se aproximan notablemente a las definiciones que las entienden como pertenecientes a una clase indiferenciada.

Bröndal afirma categóricamente que las interjecciones constituyen el fondo natural primitivo del que surge todo el lenguaje oral:

Elles sont le chaos originel, le fond naturel primitif, dont toutes les autres classes sont sorties par différenciation ${ }^{41}$.

Y, a continuación, advierte cómo las interjecciones contienen simultáneamente todos los elementos que las clases «lógicas» realizan de manera más o menos aislada. Una interjección, por lo tanto, puede ser vista desde una perspectiva sintáctica, como la concentración de una frase entera, como la expresión compleja y simultánea de un sujeto, de una cópula y de un predicado.

A pesar de todo lo anterior, Bröndal no acepta que las interjecciones constituyan meras palabras «de naturaleza». Está de acuerdo, por lo tanto, con Sapir en que, en manera alguna, se pueden identificar con los gritos puramente instintivos o con la expresión puramente animal de una emoción. Por el contrario, defiende que las interjecciones poseen una entidad convencional y que, incluso, se pueden sostener sobre cualquier clase de palabra de una lengua. Concluye que, en contra de la noción griega, las interjecciones poseen una naturaleza lógica y no solamente psicológica. Estas consideraciones no le impiden reconocer que tal categoría representa el grado más bajo y el menos diferenciado de las clases de palabras, el elemento más primitivo y más próximo a la naturaleza. Bröndal no consiente que se considere a las interjecciones

\footnotetext{
41 Bröndal, op. cit., pág. 138. «No sabemos -apunta R. Almela- si Bröndal conoció o no la Gramática General del conde de Tracy. Lo que sí sabemos es que M. Destutt, un siglo antes, había apuntado esta misma idea: '... todas las demás partes de la oración son fragmentos de ésta (de la interjección) y destinadas a descomponerla y resolverla en sus elementos», op. cit., pág. 86.
} 
como situadas fuera de la lengua (Wundt) o como una simple «orla decorativa», sino que proclama que

En réalité, les interjections doivent être regardées comme le fondement méme sur lequel repose la structure de la langue, le fonds où elle puise sans cesse, souvent certes par des voies cachées, de nouveaux éléments ${ }^{42}$

Samuel Gili Gaya también integra el estudio de las formas expresivas de emociones en el marco de la gramática e, incluso, sugiere la proximidad de este tipo de expresiones del lenguaje simple del niño o del primitivo:

La calidad subjetiva de mayores consecuencias en el lenguaje es la producida por los sentimientos. La expresión de emociones no necesita comúnmente diferenciar sus elementos; tiene carácter total y está muy cerca de la palabra-frase del niño y del primitivo. Una interjección, una blasfemia, una palabra carifósa o entusiasta, no contienen más ni menos que la expresión de la emoción particular que las motiva 4.

Las interjecciones - según Gili Gaya- son oraciones exclamativas en diferentes grados de sintetización. El proceso inverso del análisis puede llevar hasta la formación de las oraciones enunciativas:

Pueden distinguirse grados de carácter sintético de la oración exclamativa. Primero, los gritos inarticulados o las interjecciones llamadas propias (|Ah!, |Oh!, |Ay!, ¡Uy!. |Holal) que tienen validez social dentro de un grupo linguístico; palabras de todas clases habilitadas como interjecciones (|Bravol, |Animo!, |Diablo!, |Yal, etc.), o los vocativos dirigidos ya con plena intención a una persona o grupo. El segundo grupo se presentará en las frases exclamativas producidas por un comienzo de análisis de la emoción en dos o más palabras, v. gr.: ipor Dios!, ipero hombre!, thermosa noche!, iqué ascol, ipobre de mi! En último término encontramos ya el análisis más desarrollado que da a la expresión afectiva la estructura de una oración enunciativa, de la cual no se distingue más que por los recursos fonéticos arriba indicados: iNo sabia qué hacerl, iLa hora se acerca! A medida que la emotividad va perdiendo su predominio, nos hallamos ya en el terreno de las enunciativas $\$$.

Karcevsky, en su introducción al estudio de la interjección, da por supuesto que se trata de un lenguaje «natural» que el hombre no tiene necesidad de aprender:

12 BRbNDAl, op. cit., pág. 142

4 GIII GaYA, S., Curso Superior de Sintaxis Española, Barcelona, Bibliograf, S. A., 1969, pág. 41.

Ibidem. 
C'est qu'on ne doute pas un instant qu'il s'agisse ici du langage 'naturel' que l'homme n'a pas besoin d'apprendre 45 .

El estudio de esta especie de "palabras» plantea inevitablemente - según Karcevsky - el problema del signo arbitrario y del signo motivado ya tratado adecuadamente por F. de Saussure y Ch. Bally. Aunque admite el autor ruso que el signo totalmente motivado no existe en la lengua, afirma que las interjecciones constituyen el plano motivado por excelencia:

Le plan sémiologique interjectionnel est le plan du signe motivé par excellence ${ }^{46}$.

En este sentido, Karcevsky establece una división de las interjecciones en dos grandes clases: 1) exclamaciones, y 2) no exclamaciones. Un examen detenido de las últimas le lleva a reconocer que el rasgo positivo común es su carácter imitativo. Su conclusión es clara:

Le caractère motivé des interjections onomatopéiques est évident. Ce sont des images de la réalité perçue par l'oreille $47 .$. Plus on médite sur l'interjection et plus on est porté à y voir l'héritier direct, quoique bien appauvri, du signe primitif syncrétique dans lequel la voix, la mimique et le geste se fusionnaient 48 .

Hjelmslev considera que se ha ido demasiado lejos al separar las interjecciones de las partes de la oración. Acepta la posibilidad de que pertenezcan al lenguaje afectivo, pero nada impide que los elementos afectivos deban ser incluidos dentro de la Gramática:

El n'y a donc pas lieu, selon nous, de considerer l'interjection à part comme une sorte du 'langage dans le langage'. Elle peut très bien être soumise à un examen d'ordre formel, et celui-ci amène d'abord à la caser dans la catégorie de l'adverbe ${ }^{4}$.

A partir de estas o parecidas consideraciones, algunos autores, como H. Paul, defienden que las interjecciones constituyen oraciones, aunque incompletas:

\footnotetext{
45 KARCEVSKI, «Introduction à l'étude de l'interjection». Cahiers Ferdinand de Saussure, 1 (1941), pág. 57.

46 Ibidem, págs. 58-59.

47 Ibidem, pág. 62.

48 Ibidem, pág. 63. 301.

49 Huglmslev, L., Principes de grammaire générale, Copenhague, 1928, págs. 300
} 
Unter die erste klasse könter wir die Interjektionem stellem, die isoliert als unvollkommene Sätze zu betrachten sind 50 .

Otros -Bally, Tesnière...- las interpretan como «des mots-phrases de la languew ${ }^{51}$.

Jespersen advierte que lo único que todos estos elementos tienen en común es su capacidad para constituir por sí solos un enunciado ${ }^{\mathbf{5 2}}$.

Bühler ofrece varias posibilidades sin decidirse por ninguna. No sería erróneo - nos dice- incorporar a las interjecciones a un sistema de una sola clase de voces animales y humanas, y separarlas así de las palabras propiamente dichas. Ni tampoco lo sería considerarlas como adverbios, ni como frases o restos de frases ${ }^{53}$.

Vossler señala también un doble carácter de las interjecciones a partir del grado de gramaticalización que adquieran y, por lo tanto, del nivel de independencia funcional:

De ahí que la interjección oscile constantemente entre el modo de ser de las relaciones psicológicas y el de las gramaticales, dispuesta en todo momento a gramaticalizarse y en seguida a desgramaticalizarse 54 .

No faltan quienes vuelven a situarlas entre las partes de la oración. Bello, por ejemplo, que rechazó los artículos y pronombres, admite a la interjección como una de las "siete partes» y la compara a un

... verbo inconjugable, que envuelve el sujeto y está siempre en la primera persona del presente de indicativo 55 .

Todavía la Gramática de la Real Academia en su edición de 1931 la define como

... una parte de la oración que generalmente forma por sí sola una oración completa 56.

\footnotetext{
50 Paul, H., Prinzipien der Sprachgeschichte, Halle, 1937, 5.' ed., pág. 353.

51 Bally, Ch., Linguistique générale et linguistique française, Berna, 1950, 3.' ed.; Tesnikre, L., Eléments de Syntaxe Structurale, París, Klincksieck, 1976, 12.' ed.

52 JeSPERSEN, La filosofía de la gramática, Barcelona, Anagrama, 1975, pág. 93.

53 BÜhrer, K., Teoría del lenguaje, trad. por Julián Marías, Madrid, Rev. de Occidente, 1950, págs. 339, 406 y 407.

54 Vossler, K., Filosofía del lenguaje. Ensayos, trad. de Amado Alonso y Raimundo Lida, Buenos Aires, Losada, 1963, 4. ed., pág. 97.

55 Bello, A., y Cuervo, R. J., Gramática de la lengua castellana, Buenos Aires, Ed. Anaconda, 1945, pág. 340.

56 Real Academia Española, Gramática de la Lengua Española, Madrid, EspasaCalpe, S. A., 1931, pág. 126. En la primera edición (1771) la había definido como «palabra que sirve para denotar los afectos del ánimo» y afirma que «las expresiones que constan de dos o más voces, y que algunos llaman interjecciones, como:
} 
Lázaro Carreter en su Diccionario de términos filológicos la describe como "signo que puede contradecir las leyes fonológicas de una lengua..., o bien poseer una estructura fonológica correcta [...] sin valor gramatical ni semántico que desempeña las funciones lingüísticas de modo elemental» 57 .

Por el contrario, Almela Pérez sostiene que la interjección es «un fenómeno idiomático, una categoría gramatical que, gozando de un estatuto linguiístico general, se realiza o no en las diversas lenguas, y aun en las que se realiza, no lo hace de la misma forma en todas ${ }^{58}$.

Finalmente Alarcos Llorach, aplicando los resultados de la escuela de Copenhague, en especial las ideas de L. Hjelmslev y sus seguidores, reinterpreta la repetida teoría de que las interjecciones, más que partes de la oración, son oraciones enteras, por medio de la nomenclatura más coherente y científica de la doctrina glosemática:

Los pleremas anominales que no pueden regir morfemas extensos ni intensos son en general las llamadas interjecciones [...]. Estos pleremas constituyen por sí solos nexos, que, a diferencia de los nexos normales, no pueden ser analizados en una base y una característica: ah, bah, ea... 59 .

Como conclusión, debemos reconocer que los grandes interrogantes sobre el origen del lenguaje y sobre su naturaleza íntima, que han preocupado a linguiistas y filósofos a lo largo de toda la historia de ambas ciencias, no han perdido su vigencia.

Se han venido repitiendo persistentemente respuestas que, en ocasiones, sólo difieren por el léxico con que son formuladas pero que, en definitiva, no explican ni resuelven de manera concluyente los problemas planteados. La interjección, con su fuerza expresiva y su simplicidad formal y funcional, pone de manifiesto de modo ejemplar, que el lenguaje, facultad exclusivamente humana, seguirá constituyendo un objeto de investigación y discusión permanente ${ }^{60}$.

\section{José Antonio HeRnandez GuerRero}

\footnotetext{
gracias a Dios, bendito sea Dios, Jesús mil veces, y otras semejantes, no deben considerarse como interjecciones, sino como verdaderas oraciones que, cuando más, necesitan suplemento de algún verbo" (págs. 226-227). Edición de Ramón Sarmiento, Editora Nacional, Madrid, 1984.

5 LAzaro Carreter, F., Diccionario de términos filológicos, Madrid, Gredos, 1971, página 1997.

58 Almela, R., op. cit., pág. 58.

59 Alarcos Llorach, E., Gramática estructural, Madrid, Gredos, 1974, págs. 8485.

60 Rojas, E. M., La Interjección: sus formas en el español hablado, Tucumán, Argentina, Facultad de Filosofía y Letras, 1981.
} 